\title{
A student-centered approach to vocabulary building using Popplet, Pages and Puppet Pals
}

\author{
Sarah Hopkyns \\ Timothy Nicoll \\ Zayed University, UAE
}

\section{Introduction}

Perhaps the most important and most tangible area of learning through the medium of a second language in any subject area is that of vocabulary and terminology. As Khoii and Sharififar (2013) state, "vocabulary is a core component of language proficiency and provides much of the basis for how well learners communicate with each other" (p. 199). Indeed, "without grammar, very little can be conveyed; without vocabulary, nothing can be conveyed" (Wilkins, 1972, p. 111).

In learning a new subject at college/university, students need to master the terminology of their field as well as language for academic purposes (Turlik, 2013). They normally meet this vocabulary in the context of reading or listening about their subject, but new terms may also be presented and explained directly; in English teaching, traditionally new vocabulary in textbooks is often presented in the form of lists followed by a gap-fill or matching activity. Whether or not this vocabulary is memorable or not often depends on whether the learners are engaged by the sentences or text surrounding the new lexis: if the topic is not of interest or not comprehensible to the learner, the words can easily be passed over and forgotten. If learners are able to choose the words they learn and the context in which these words appear, however, the words are personalized and so more memorable. What is preferable is to achieve what Tickoo (2003) calls "a 'web of associations' of different kinds which give every new word, word form and word meaning a strong base in the learner's mind" (p. 216) - the kind of web which underlies 'Deep Learning' (Stanger-Hall, 2012) in any subject.

With the introduction of iPads in the classrooms in the Academic Bridge Program at Zayed University, Abu Dhabi in September 2012, the faculty members were encouraged to think outside the box when it came to all areas of language learning. Using a variety of applications (apps) that had been downloaded onto all the students' iPads at the start of the semester enabled instructors to experiment with teaching and learning tools that had previously been unavailable on a wide scale. A vast range of new ideas arose from this opportunity, and in the area of vocabulary in particular, mobile devices such as the iPad have certainly had a dramatic impact on learning at Zayed University. It is true to say that, "the future is increasingly mobile, and it behoves us to reflect this in our teaching practice" (Hockly, 2013, p. 83).

This paper gives a reflection on a particularly effective workflow lesson combining three iPad apps used for vocabulary building: Popplet, Pages and Puppet Pals. Through this three-step workflow lesson, these apps can be used together to help students brainstorm related lexical items, draw from this vocabulary to create dialogues with guidance from the teacher, and then to act out these dialogues by choosing characters, props and backdrops, and the recording of their voices using the unique movie-making app Puppet Pals.

Before explaining how the workflow works, the specific context of the study will be outlined. Then the individual steps of the workflow and features of the apps will be explored before presenting feedback 
from ten teachers and twenty-four students who were surveyed and interviewed regarding their opinions on the workflow. The paper's conclusion will include ways in which the workflow can be adapted to suit a wide range of purposes.

\section{Context}

The context for this workflow was the Academic Bridge Program (ABP) of Zayed University. The ABP exists to bridge the gap that exists for some students between the English level they have reached upon finishing secondary school, and that required to succeed in the baccalaureate program they will begin in ZU's University College. Most students are Emirati and generally school leaving age, although there are also mature students who have decided to return to university to continue their learning. Although there are both male and female students studying in the ABP program in two separate sides of the university, we have so far used the workflow only with the female students.

The ABP has six levels, as stated in the University website:

Depending on where they enter the ABP, a student may spend between one term (entering at the highest level) and two years (entering at the lowest level) improving their English in the ABP. $B y$ the end of their time in the program students are ready to be successful, independent learners in the baccalaureate program of the university.

(Zayed University website, retrieved 20/04/13)

The program therefore seeks not only to raise the English level of the students but also to equip them with the other skills that they will need to be successful in the rest of their time in the university, including their ability to use and incorporate technology in their learning, as well as their general knowledge base. In the case of our study, the students involved in the workflow were all in the highest level of the ABP, Level 8.

\section{Key concepts}

Underpinning our belief in the value of this workflow, is research showing the importance of vocabulary in student's language learning, be it for the receptive skills of listening and reading, or the productive skills of speaking and writing. As Richards $(2008$, p. 5$)$ puts it, "learners need a large vocabulary and a good working knowledge of sentence structure to process texts bottom-up". As well as needing a large vocabulary, learners also need to know individual lexical items very well. This is often referred to as "the quality or 'depth' of vocabulary and is as important as vocabulary size" (Schmitt, 2010, 15).

In addition, anecdotally teachers are very familiar with students lamenting that they lost track while listening, owing to being stuck on a particular word. Examiners of tests such as IELTS and TOEIC are equally familiar with candidates becoming derailed in their speaking due to their inability to use the word they want to in order to express what they want to say. It becomes clear from these varied situations that vocabulary plays a key role in language proficiency.

Another vital element in the teaching and learning of vocabulary is that of contextualization. This provides the soil in which the word can take root in the mind of the learner. In addition, it has been shown that as well as students having a better retention of words taught and learned in a contextualized way, learning words in a categorized way is also important. As Thornbury (2002) puts it, "acquiring a vocabulary requires not only labelling but categorizing skills" (p. 18). The effectiveness of word diagrams in remembering words was noted by Gairns \& Redman as far back as 1992, but advances in technology mean that we now have a variety of apps at our fingertips to facilitate this. 
A further key concept with regards to effective vocabulary building is personalization. If learners are able to make the language their own, rates of retention are higher. In short, "making vocabulary personal helps to make it more memorable" (McCarten, 2007, p. 22).

The final concept underlying our workflow was that learning through integrated skill use is better for students, so a range of speaking, listening, reading, and writing elements were included. As Newton (2001) explains, through communication tasks for vocabulary expansion, "learners meet language in ways that encourage the construction of multiple associations between old and new knowledge in their lexical systems" (p. 36). The key concepts above encapsulate a student-centered approach, which is at the core of our workflow.

\section{Methods}

The workflow was designed to follow a three-step process including brainstorming, discussion and writing a dialogue and then performing this dialogue. The details for each step are highlighted below.

\section{Step 1 - Using Popplet for brainstorming}

The first application used in the workflow is Popplet, which is commonly used for brainstorming and creating mind maps. It is available in a free 'lite' version or a paid version; for our classes we used the 'lite' version, which is easily downloadable from Apple's App Store.

\section{my popplet}

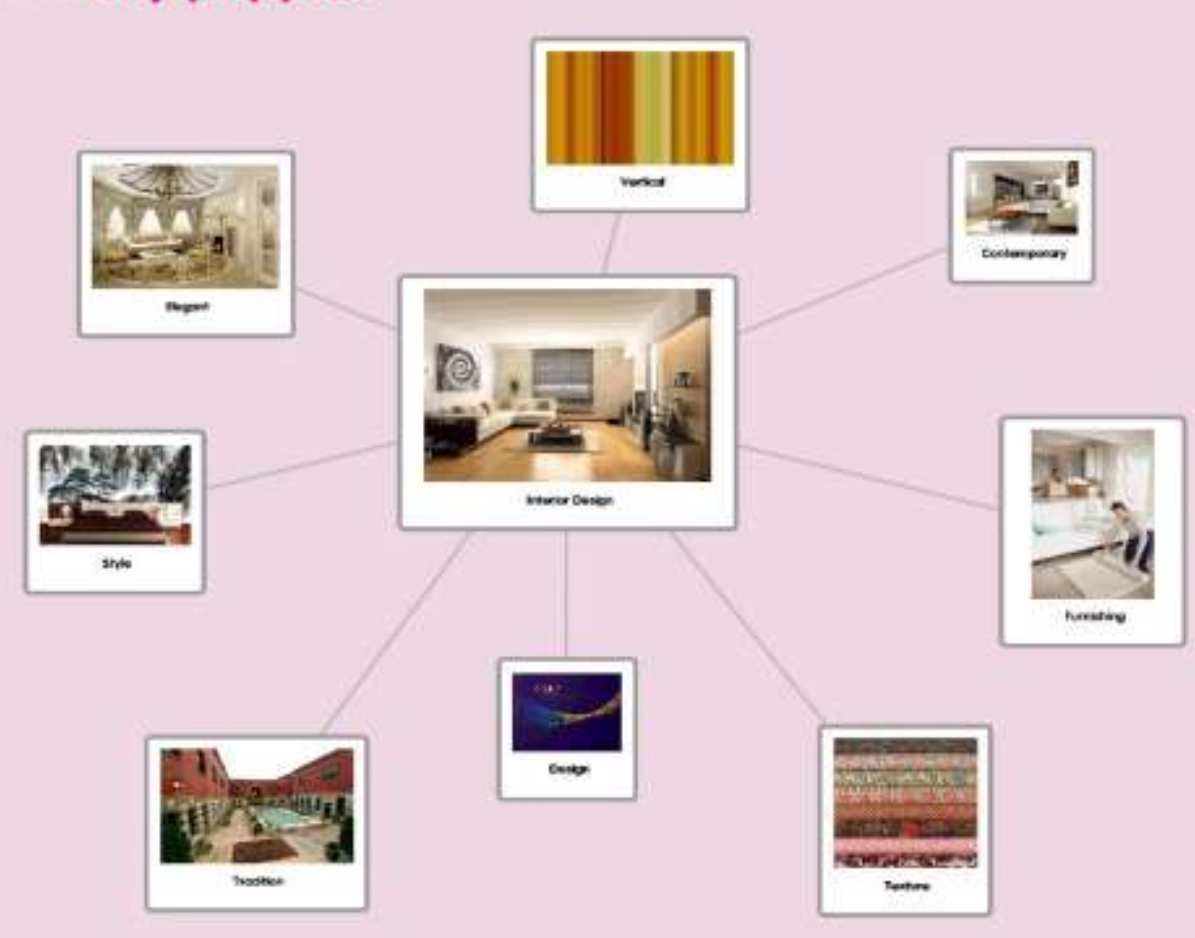

Figure 1: Sample student mind map: interior design vocabulary (Popplet)

For the purpose of vocabulary building, various approaches can be taken. Generally, a key word or topic area is given, and then Popplet can be used either to draw upon the existing schemata of the students, or to have them brainstorm key related lexis that has been pre-taught. Thus, in the first case the app is 
being used to see which words the students know related to the topic, while in the second is used to see what words they select as being most important.

Figure 1 shows an example. The approach taken for the workflow in the example above was to centre the Popplet mind map around the topic of Interior Design and then ask the students in groups to choose eight words from the 33 they had been taught. When constructing the mind map, the students were free to negotiate in groups on the 8 words they thought most important, with no input from the teacher on this question. They could include images as well as the words themselves on the mind map.

\section{Step 2 - Using Pages to create a dialogue}

Following the successful negotiation of words and construction of the mind maps in groups, the students were directed to the second app in the workflow, Pages. The students used this to construct a dialogue using the selected lexis, which would then be the basis of a video created using the Puppet Pals app in Stage 3. To help the students in the writing of the dialogue, they were instructed to imagine a scenario in which two or more people might use these words in a conversation, in one or more locations. It was stressed that the conversation did not have to be attributed to themselves if they did not wish. Students were also told that they would be using Puppet Pals next and could show the location either with one of the pre-existing backdrops or with a picture. Figure 2 shows an example.

The advantage of Pages for the workflow is that it is a fully functioning word processing app, which is available on all of the iPads of the students in Zayed University's Academic Bridge Program. When writing the students were encouraged to brainstorm first and make notes, before starting to draft their dialogue, and while this went on, the teacher monitored closely and gave assistance as required.

\section{Interior Design Dialogue}

Sooky: Hello Sara.

Sara: Hello Sooky.

Sooky: Can you help me to design my room?

Sara: Yes, of course.

Sooky: So, what can I do to make my room contemporary?

Sara: You can furnish your room with elegant elements such as a square table, a flower painting and calm lights.

Sooky: Should I create a workspace in my room?

Sara: Yes, but you have to harmonize the furniture and the size of the room to make it balanced.

Sooky: Thank you for helping me.

Sara: You're welcome.

Figure 2: Sample student dialogue (Pages). 


\section{Step 3 - Using Puppet Pals to create a movie}

In the final stage of the workflow, students took the dialogue they had created in stage 2 (based around the words in stage 1) and then created a video voiced by themselves in the Puppet Pals app (see e.g. Figure 3). For this we used the original app and not Puppet Pals 2, as the original was one of the apps (like Pages) selected for free installation on students' iPads in the university. This meant that the students all had the 'Director's Pass - All Access' version, which means a fuller selection of actors and backdrops for them to work with. In addition, many of the students had already used the app in some form already, so it meant that less time was needed for the teacher to set the stage. This is an important factor to consider when using apps with students in classes, as considerable time can sometimes be spent ensuring that all students have the app, that settings on the iPad are correct (e.g. that the app has been cleared to use the camera roll of the device in iPad's settings), and also that the app has been demonstrated if never used before. However, what is also true is that the students learn quickly, and great use can be made of peer teaching in this regard.

When constructing their video, the Puppet Pals app allows the students to either voice the dialogue using one of the stock characters contained within the app or else import pictures from their cameras or the web. This also applies to the backdrops that can be used. In the case of our students, many groups decided to base the dialogues around people standing inside buildings and looking at the design features of the space. A strength of Puppet Pals is that it also allows for multiple backdrops within the video. For this part of the process, some students felt shy about doing the dialogue with other students listening, so an option is to allow them some time to go to an area outside the classroom to record it in private, and then return in a designated time. This also deals with the problem of background noise being picked up by the iPad's microphone.

The usual ending of this stage, once all of the groups have finished their videos, sees the class watching all of the dialogues together on the class projector. This can be the first time for the students to see the different vocabulary that the other groups selected and apart from the enjoyment gained from the students of having their work displayed, allows the vocabulary to be shared in a contextualized, personalized and memorable way.

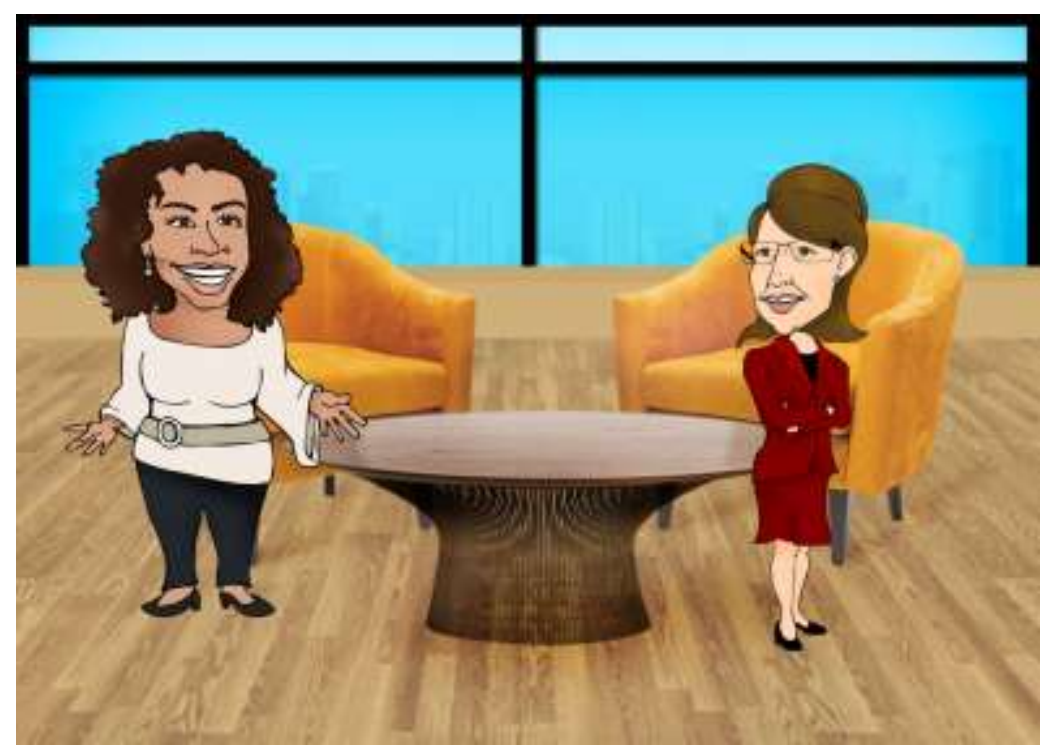

Figure 3: Sample student visual (Puppet Pals). 


\section{Evidence of effectiveness}

Although the workflow had worked well in our lessons, we wanted to find out the opinions of other teachers and also the thoughts of students. Ten teachers who were teaching a range of levels in the ABP program were asked to use the workflow with their classes and then participate in a semi-structured interview asking for their experiences and feedback. Similarly, twenty-four students from Level 8 classes (Upper-intermediate/advanced) were surveyed. For both groups, three key questions were asked:

1. Do you think this workflow (Popplet > Pages > Puppet Pals) is effective?

2. What are the best aspects of the workflow?

3. What are some drawbacks of the workflow?

\section{Is this workflow effective?}

When asked whether or not the workflow was effective, the responses from both the teachers and the students were overwhelmingly positive. As can be seen from Figure 4, 95\% of students felt the workflow was effective and $90 \%$ of teachers felt the same. This was encouraging feedback and reasons for these opinions were explored in more detail in the next two questions.

\section{Students}

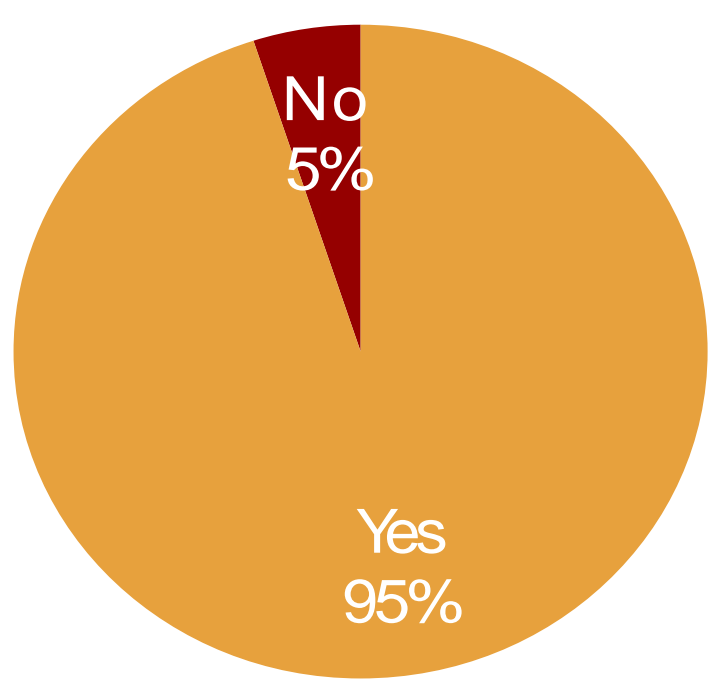

Teachers

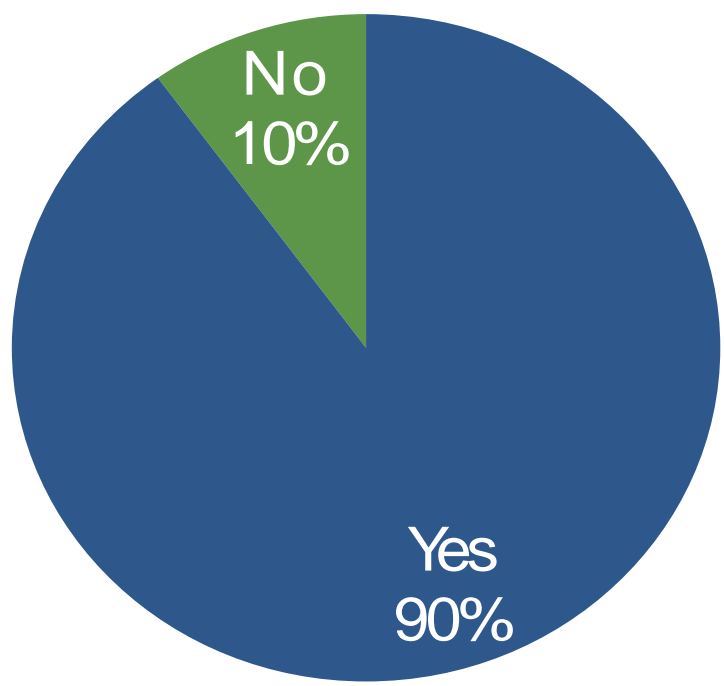

Figure 4: Responses to Do you think the workflow is effective?

\section{What are the best aspects of the workflow?}

Due to the fact that the vast majority of students and teachers interviewed and surveyed felt the workflow was effective, there was a plethora of comments on the positive features of the apps and the way these apps were used in combination. The three most popular opinions for each group are highlighted in Table 1. 
Table 1: Responses to What are the best aspects of the workflow?

\begin{tabular}{|l|l|}
\hline \multicolumn{1}{|c|}{ Students } & \multicolumn{1}{|c|}{ Teachers } \\
\hline $\begin{array}{l}\text { It is fun to brainstorm ideas and then create a } \\
\text { show with classmates. }\end{array}$ & $\begin{array}{l}\text { It is a great way to put vocabulary into context. } \\
\text { Students seem to enjoy the creativity of choosing } \\
\text { the context themselves. }\end{array}$ \\
\hline $\begin{array}{l}\text { It is great that you can use your own characters } \\
\text { and backgrounds. This makes each show very } \\
\text { different. }\end{array}$ & $\begin{array}{l}\text { There is a high level of student engagement. They } \\
\text { are using their iPads and working collaboratively. }\end{array}$ \\
\hline $\begin{array}{l}\text { It is more comfortable than acting out a dialogue } \\
\text { in person. We can use different identities. }\end{array}$ & $\begin{array}{l}\text { Personalizing the language makes it more } \\
\text { memorable. Students use the new vocabulary over } \\
\text { and over again as part of the discussion process }\end{array}$ \\
\hline
\end{tabular}

As can be seen from Table 1, the best aspects of the workflow support the aims of the workflow in that it was seen as a fun, engaging, personalized and memorable way to learn vocabulary.

\section{What are some drawbacks of the workflow?}

As well as looking at the best aspects of the workflow, we were also curious to find out about any perceived problems, mainly in order to find ways around these problems in the future. The main comments are summarized in Table 2.

Table 2: Responses to What are some drawbacks of the workflow?

\begin{tabular}{|l|l|}
\hline \multicolumn{1}{|c|}{ Students } & \multicolumn{1}{|c|}{ Teachers } \\
\hline $\begin{array}{l}\text { The noise levels in the classroom can make } \\
\text { recording voices difficult in the final stage. }\end{array}$ & $\begin{array}{l}\text { Students could be discourages from using Puppet } \\
\text { Pals, seeing he cartoon-like characters as one- } \\
\text { dimensional. }\end{array}$ \\
\hline $\begin{array}{l}\text { If you press the 'back' button in puppet Pals by } \\
\text { mistake, you lose all your work. Be careful! }\end{array}$ & $\begin{array}{l}\text { A lot of the characters and backdrops are based in } \\
\text { Puppet Pals are based on American history and } \\
\text { culture (e.g. Thanksgiving, Christmas, Political } \\
\text { Parties, and Talk shows) }\end{array}$ \\
\hline $\begin{array}{l}\text { It can be time-consuming. The workflow can take } \\
\text { around 60-90 minutes to complete. }\end{array}$ & $\begin{array}{l}\text { It is difficult to email videos that are longer than a } \\
\text { minute. }\end{array}$ \\
\hline
\end{tabular}

As can be seen from Table 2, a lot of the drawbacks focus on design flaws of particular apps. With Puppet Pals 2 having been recently introduced, although not yet freely available to the Zayed University students, some of these problems have been ironed out, such as the one-dimensional nature of the characters in Puppet Pals. Solutions for background noise in the classroom and time taken would be to use another space such as the library or an empty classroom for the recordings. The first time the workflow is used it takes time to learn how to use the apps, as mentioned earlier; however, the more familiar the learners are with it, the quicker the stages become. An interesting point regarding the culturally biased characters available in the Puppet Pals app was made by several of the teachers. To avoid this, the students can chose the option of using completely unique characters from their camera rolls. This makes the shows highly personalized and allows for a range of identities to be used. 


\section{Conclusion}

In conclusion, this article shows the advantage that can be gained from combining a number of apps together on an iPad or mobile device in order to maximize the potential and strengths of each app. This is just one of many workflows that can be created on the iPad, but we believe this one can be used in a number of different ways in teaching vocabulary in English Language Teaching (ELT) as well as other disciplines. For example, in ELT, apart from the vocabulary building purpose for which we applied the workflow, it would also work well for teaching different grammar or functional areas. In this case the first stage could see the mind map based around verbs in a particular tense, or functional language. The workflow incorporates the memorable aspects of using mind maps for learning vocabulary; whilst also allowing for personalization of the target language in a contextualized setting. Finally, it follows an integrated skills approach that includes a combination of reading, writing, listening and speaking.

For other disciplines, the workflow would work well for generating thoughts and discussions around certain topic areas. For example, if a class were discussing a particular period in history or event, then Popplet could be used to brainstorm some of the key issues, or factors relating to that event. Then Pages could be used to construct a dialogue either between two people discussing the event now, or even two people at the time. Finally, Puppet Pals could be used to show the dialogue in any setting of the students' pleasing. One strength is that this allows students to take themselves out the equation and attribute opinions to the actors in the video that they may hold themselves but be unwilling to voice openly. Moreover, the possibility of creating a dialogue and video set around people at the time really adds reality and context to the topic, making it more interesting and memorable for the students.

In summing up, we believe there is a great advantage in using multiple apps in a workflow on the iPad. Many apps lack the functionality to base a whole lesson around them, but used in conjunction and taking their advantageous features together, can be highly effective. The example on which we have focused in this paper is that of vocabulary building, but we can see the workflow being successful in other topic areas in various disciplines. In fact, the possibilities are to a large extent only limited by the imagination of the teacher using them. We are sure that repeated use will see a blossoming of ideas generated by the classes they are used with, which will mean future classes will benefit from an expanded range of uses.

\section{References}

Gairns, R. \& Redman, S. (1992) Working with words: a guide to teaching and learning vocabulary. Cambridge: Cambridge University Press.

Hockly, N. (2013). Mobile learning. ELT Journal, 67(1), 80-84.

Khoii, R. \& Sharififar, S. (2013). Memorization verses semantic mapping in L2 vocabulary acquisition. ELT Journal, 67(2), 199-209.

McCarten, J. (2007). Teaching vocabulary: lessons from the corpus, lessons for the classroom. New York: Cambridge University Press.

Newton, J. (2001) Options for vocabulary building through communication tasks, ELT Journal, Volume 55/1 30-37.

Richards, J. (2008). Teaching listening and speaking: from theory to practice. New York: Cambridge University Press.

Hopkyns, S. \& Nicoll, T. (2013). A student-centered approach to vocabulary building using Popplet, Pages and

Puppet Pals. Learning and Teaching in Higher Education: Gulf Perspectives, 10(2). http://Ithe.zu.ac.ae 
Schmitt, N. (2010). Researching vocabulary: a vocabulary research manual. Basingstoke: Palgrave Macmillan.

Stanger-Hall, K.F. (2012). Multiple-choice exams: an obstacle for higher-level thinking in introductory science classes. CBE: Life Sciences Education, 11(3), 294-306.

Tickoo, M. L. (2003) Teaching and Learning English, New Delhi: Orient Longman.

Thornbury, Scott (2002) How to Teach Vocabulary, Harlow: Longman.

Turlik, J. (2013). The use and development of academic vocabulary in second language writing: a longitudinal investigation. Learning and Teaching in Higher Education: Gulf Perspectives, 10(1). http://the.zu.ac.ae

Wilkins, D. A. (1972) Linguistics and language teaching, London: Edward Arnold.

Zayed University Website. (2013). http://www.zu.ac.ae/main/en/colleges/colleges/abp/index.aspx 